\title{
O Cidadão e a Ouvidoria Geral do SUS: Análise das Demandas Protocoladas no Disque Saúde em 2011
}

\section{The Citizen Ombudsman and SUS: Review of Claims filed in Health Disque in 2011}

\section{El Defensor del Pueblo y Ciudadano SUS: Examen de reclamaciones, presentadas en Disque Salud en 2011}

Rebecca Lucena Theophilo ${ }^{1}$ Sandra Mara Campos Alves ${ }^{2}$

\section{RESUMO}

Numa gestão democrática participativa, a Ouvidoria aparece com um espaço de escuta dos cidadãos, assim este trabalho apresenta uma análise das demandas protocoladas no Disque Saúde, um setor do departamento da Ouvidoria Geral do SUS, responsável em atender os cidadãos para disseminar informações de saúde e também registrar reclamações, elogios, denúncias e sugestões. Através de uma pesquisa quali-quantitativa, foi utilizado na coleta de dados, procedimentos de pesquisa documental e bibliográfica. Concluindo que a importância da participação cidadã consolida cada vez mais a gestão a fim de tornar as politicas públicas em saúde mais efetivas.

Palavras Chave: Democracia; Políticas

1 Especialista em Direito Sanitário pela Fundação Oswaldo Cruz Brasília. Colaboradora do Departamento de Ouvidoria Geral do SUS do Ministério da Saúde.

2 Pesquisadora Colaboradora do Programa de Direito Sanitário da Fundação Oswaldo Cruz Brasília, advogada, Mestre em Política Social pela UnB e especialista em Direito Sanitário pela Fundação Oswaldo Cruz Brasília.
Públicas; Participação cidadã.

\section{ABSTRACT}

In a democratic participatory management, theOmbudsmanappearswithaspace forlistening to the citizens. This paper presents an analysis of the claims filed in the "Disque Saúde", a sector of the Ombudsman Department of SUS that is responsible to attended citizens. This Departament disseminates health information and also registers complaints and suggestions. It was made a qualitative and quantitative research by a collecting data, researching procedures and documenting literature. Concluding that the importance of citizen participation consolidates increasingly managing to make public health policies more effective.

Keywords: Democracy; Public Policies; Citizen Participation.

\section{RESUMEN}

En una gestión participativa democrática, el Defensor del Pueblo aparece con un espacio para escuchar a los ciudadanos, por 
lo que este artículo se presenta un análisis de las alegaciones presentadas en la Línea de la Salud, un sector del Departamento de Ombudsman SUS, ciudadanos responsables a servir en la difusión de información sobre la salud y también registrar quejas, felicitaciones, quejas y sugerencias. A través de un estudio cualitativo y cuantitativo se utilizó para recopilar datos, protocolos de investigación y la literatura documental. Concluyendo que la importancia de la participación ciudadana consolida cada vez más la gestión para que las políticas de salud pública más eficaz.

Palabras Clave: democracia; políticas públicas; participación ciudadana.

\section{INTRODUÇÃO}

A cidadania é concretizada pela participação, pelas expressões de vontades e necessidades de cada indivíduo, fato que torna o cidadão o principal autor da democracia participativa.

Com o processo de redemocratização brasileira nos anos de 1980 o ideal democrático e participativo foi consolidado dispondo sobre inúmeras formas de participação direta do cidadão, com destaque para a participação da comunidade como diretriz organizativa do Sistema Único de Saúde.

Com o surgimento das Ouvidorias, a valorização da cidadania e o processo de uma gestão participativa vão se consolidado a fim de tornar as políticas públicas de saúde mais efetivas para os cidadãos.

O objetivo deste artigo é mapear e analisar as demandas protocoladas na Central de Pesquisa e Acolhimento Humanizado de Manifestações, chamada também de DISQUE SAÚDE, da Ouvidoria Geral do Sul do Ministério da Saúde, durante o ano de 2011.

A presente pesquisa foi divida em quatro partes, onde na primeira foi feita uma breve contextualização do que é democracia, levando-se em conta o processo democrático brasileiro e a participação cidadã. Na segunda parte, a explanação é sobre a Ouvidoria em Saúde no Brasil, com foco no Departamento de Ouvidoria Geral do SUS detalhando os canais de escuta ao cidadão.

Em seguida, são apresentados os resultados da pesquisa empreendida no DISQUE SAÚDE no ano de 2011.

Por fim, apresenta-se a conclusão com os principais assuntos mais demandados na Ouvidoria, relacionando-os com a importância desse canal de participação para efetivação da democracia participativa no âmbito do SUS.

\section{OUVIDORIAS COMO ESPAÇO DE DEMOCRACIA}

Para Bonavides $^{(1)}$, a democracia é uma forma de exercício da função governativa em que a vontade soberana do povo decide, direta ou indiretamente, todas as questões de governo, de modo que o povo seja sempre o titular e o objeto, o sujeito ativo e o sujeito passivo do poder legítimo. Nesse sentindo, a democracia viabiliza a participação cidadã, que para se concretizar faz-se necessário, espaços consolidados e fortalecidos para se fazer cumprir o papel de democratização do processo de tomada de decisões em áreas de políticas públicas específicas, criando condições para superação de problemas oriundos de uma 
politica centralizadora.

A participação cidadã, processo complexo e contraditório, apresenta uma sociedade civil forte e autônoma, com atuação organizada de indivíduos, grupos ou organizações, voltada para a redefinição do papel do Estado e das suas instituições.a partir da relação da própria sociedade civil com o Estado e o mercado ${ }^{(2)}$.

Para alcançar essa participação cidadã, necessária a articulação entre os mecanismos institucionais já existentes em nosso sistema representativo, e os mecanismos de participação semi-direta criados pelas organizações e movimentos sociais, ao longo do processo democrático brasileiro.

A participação cidadã trás ainda a dimensão educativa da participação, e o papel de controle social e político do Estado pela sociedade civil $^{(2)}$, o que demonstra que a participação é capaz de forjar um novo cidadão, e, por conseguinte uma nova sociedade civil, mais forte, mais responsável e mais ciente de seu papel transformador.

Paraalcançaralgumasdessastransformações, e exigir a aplicação dos seus direitos de forma eficaz, a sociedade pode utilizar o seu poder de comunicabilidade, e para tanto, fazer usos de mecanismos de participação já estabelecidos, como o caso da Ouvidoria.

Escutar os desejos e anseios da população para melhor pautar as políticas de Estado deveria ser conduta corrente, em especial em estados democráticos. Para satisfazer as exigências da democracia, os direitos nela inerentes devem realmente ser cumpridos e, na prática, devem estar à disposição dos cidadãos (p. 62) ${ }^{(3)}$.

Historicamente, a figura do ouvidor teve origem na Suécia, no final do século XVIII e início do século XIX. Nessa época o representante do rei, cuja função era vigiar e executar as ordens emanadas pelo monarca teve seu papel modificado para o de mandatário do parlamento com a nova função de "controlar em nome própria a administração e a justiça" (p. 7) $)^{(4)}$. Todavia, apenas em 1809, a figura do Ombudsman foi positivada na Constituição da Suécia.

Para Riche ${ }^{(5)}$, ouvidorias públicas devem conhecer os anseios da sociedade, dar voz aos que não têm vez, aos invisíveis, promover $\mathrm{o}$ acesso à informação como um dever do Estado e um direito do cidadão com o intuito de transformar a cultura do segredo e da segregação na cultura da transparência e da democracia participativa.

O grande destaque que se dá ao modelo democrático participativo é que nele o cidadão deixa de ser mero espectador, em que seu papel era restrito à escolha dos líderes, para ser ator principal no processo de construção política. A democracia participativa defende um maior envolvimento da população nos processos decisórios como uma forma de diminuir as diferenças da formação política da opinião advindas com o modelo capitalista, mas sem deixar de lado os institutos da democracia representativa, já existentes $(\mathrm{p} .46)^{(6)}$.

Assim, as Ouvidorias tornaram-se um instrumento essencial para a valorização da cidadania e para o aperfeiçoamento do processo de democratização da sociedade, subsidiando a gestão, que se utiliza da voz do povo, do grau 
de satisfação e aplicabilidade das políticas públicas para (re) formulá-las.

$\mathrm{Na}$ América Latina, acompanhando o processo de redemocratização tardia, a implantação do instituto só começou a ser observada nas duas últimas décadas do século $\mathrm{XX}^{(4)}$.

\subsection{Ouvidoria em Saúde no Brasil}

No Brasil, país de democratização tardia, o processo não foi distinto. Ainda que sejam observados registros na história brasileira da figura de ouvidores, apenas em 1986, por meio do Decreto $\mathrm{n}^{\circ} 92.700$ de 21 de maio de 1986, foi instituído o cargo de ouvidor geral da Previdência Social ${ }^{(4)}$.

Ao ouvidor deveriam então ser levadas denúncias, queixas e informações dos usuários do então nominado Sistema Nacional de Previdência e Assistência Social, a quem cabia zelar pela boa administração desse Sistema.

Todavia, as ouvidorias só se tornaram uma realidade no cenário brasileiro a partir da promulgação da Carta Magna de 1988, que dispõe sobre inúmeras formas de participação e controle social, com destaque para a participação da comunidade como diretriz organizativa do Sistema Único de Saúde.

No campo da saúde, a origem desse sistema de ausculta do povo se dá a partir do enfrentamento da pandemia de HIV/AIDS, a partir dos anos de 1996, onde se criou um serviço de Tele Atendimento no Ministério da Saúde - DISQUE AIDS - como objetivo de responder aos questionamentos da população sobre o HIV/AIDS e outras doenças sexualmente transmissíveis.

O grande volume de ligações denuncia a necessidade de expansão e transformação do serviço que se inicia no ano de 1997, com o surgimento de um novo serviço intitulado Disque Saúde.

Consistente também num serviço de discagem gratuita o Disque Saúde não se restringe apenas ao tema das doenças sexualmente transmissíveis, e passa a abordar outras questões de saúde, além de passar a registrar e receber denúncias, reclamações e sugestões dos usuários do SUS.

Como desdobramento, se observa ainda em 2002 a criação do Centro Nacional de Promoção da Qualidade e Proteção aos Usuários do Sistema Único de Saúde - PRÓ-SAÚDE, por meio do Decreto $\mathrm{n}^{\mathrm{o}} 4.194$ de 11 de abril de 2002. O PRÓ-SAÚDE coordenou a execução inicial da Política Nacional de Ouvidorias do SUS, com a intenção de integrar as três esferas de governo em benefício do usuário do Sistema Único de Saúde (SUS).

Esse novo espaço, criado dentro de uma nova cultura democrática, tinha como objetivo não apenas obter informações, mas de um verdadeiro espaço de participação do cidadão, onde fosse possível colocar seu ponto de vista, dúvidas e críticas à gestão.

O tema das Ouvidorias foi também pautado na $13^{\mathrm{a}}$ Conferência Nacional de Saúde, em 2003, e no seu Relatório Final estabelece no item 65 do Eixo III, que o Ministério da Saúde e as Secretárias Estaduais de Saúde devem viabilizar a implantação e implementação de Ouvidorias com Disque Saúde (7). 
Posteriormente, por força do Decreto $\mathrm{n}^{\mathrm{o}}$ 4.726 de 9 de junho de 2003, o PRÓ SAÚDE foi substituído pelo Departamento de Ouvidoria Geral do SUS, ligado à Secretaria de Gestão Participativa. O Departamento de Ouvidoria Geral do SUS tinha, entre outras atribuições, a de proposição, coordenação e implementação da Política Nacional de Ouvidoria em Saúde, no âmbito do SUS, estimulando a criação de estruturas descentralizadas de ouvidorias, bem como a participação dos usuários e entidades da sociedade na avaliação dos serviços prestados pelo SUS ${ }^{(8)}$.

Atualmente a estrutura organizacional do Ministério da Saúde é regulamentada pelo Decreto $\mathrm{n}^{\mathrm{o}} 7.797$ de 30 de agosto de 2012, que manteve o Departamento de Ouvidoria Geral do SUS - DOGES, com praticamente as mesmas competências. O DOGE está ligado à Secretaria de Gestão Estratégica e Participativa, que tem como um dos seus objetivos o fortalecimento da participação e do controle social em saúde (9).

O DOGES é composto ainda por duas coordenações: a) Coordenação Geral do Sistema Nacional de Ouvidoria (CGSNO), responsável por coordenar no âmbito federal o Sistema Nacional de Ouvidoria do SUS, e por garantir a descentralização das Ouvidorias Estaduais e Municipais; e b) Coordenação Geral de Pesquisa e Processamento de Demandas (CGPEP), que é responsável pelo acolhimento e tratamento de todas as demandas dos cidadãos, pelas pesquisas, e pela gestão das informações do departamento.

É na CGPEP que está localizada a Central de Acolhimento Humanizado de Manifestações da Ouvidoria Geral do SUS, chamada também de DISQUE SAÚDE (Figura 1).

O DISQUE SAÚDE é canal gratuito de comunicação, que atende pelo número telefônico 136. Esse número de contato é amplamente divulgado em todos os cartazes e publicações do Ministério da Saúde.

Através do DISQUE SAÚDE a população pode receber informações específicas sobre saúde, programas do Ministério da Saúde, além de poder registrar reclamações, denuncias, solicitações, sugestões e elogios.

Relatório Gerencial produzido pelo Departamento de Ouvidoria Geral do SUS em 2011 demonstra que o canal de entrada mais acessado pelos cidadãos na Ouvidoria Geral do SUS é o DISQUE SAÚDE, com 46,2\% dos registros ${ }^{(10)}$.

Observa-se, portanto que a Ouvidoria do SUS, por meio de seus inúmeros canais, em especial o DISQUE SAÚDE, é um importante instrumento de colaboração com a gestão participativa, pois trás insumos importantes que o gestor deve levar em consideração no seu processo de tomada de decisão.

Diante desse dado, foi empreendida pesquisa com o objetivo de investigar quais as principais demandas protocoladas no Disque Saúde, no ano de 2011.

\section{METODOLOGIA}

Trata-se de uma pesquisa quali-quantitativa que utilizou, na coleta de dados, procedimentos de pesquisa documental e bibliográfica.

A pesquisa documental foi realizada a partir dos dados armazenados no Sistema 


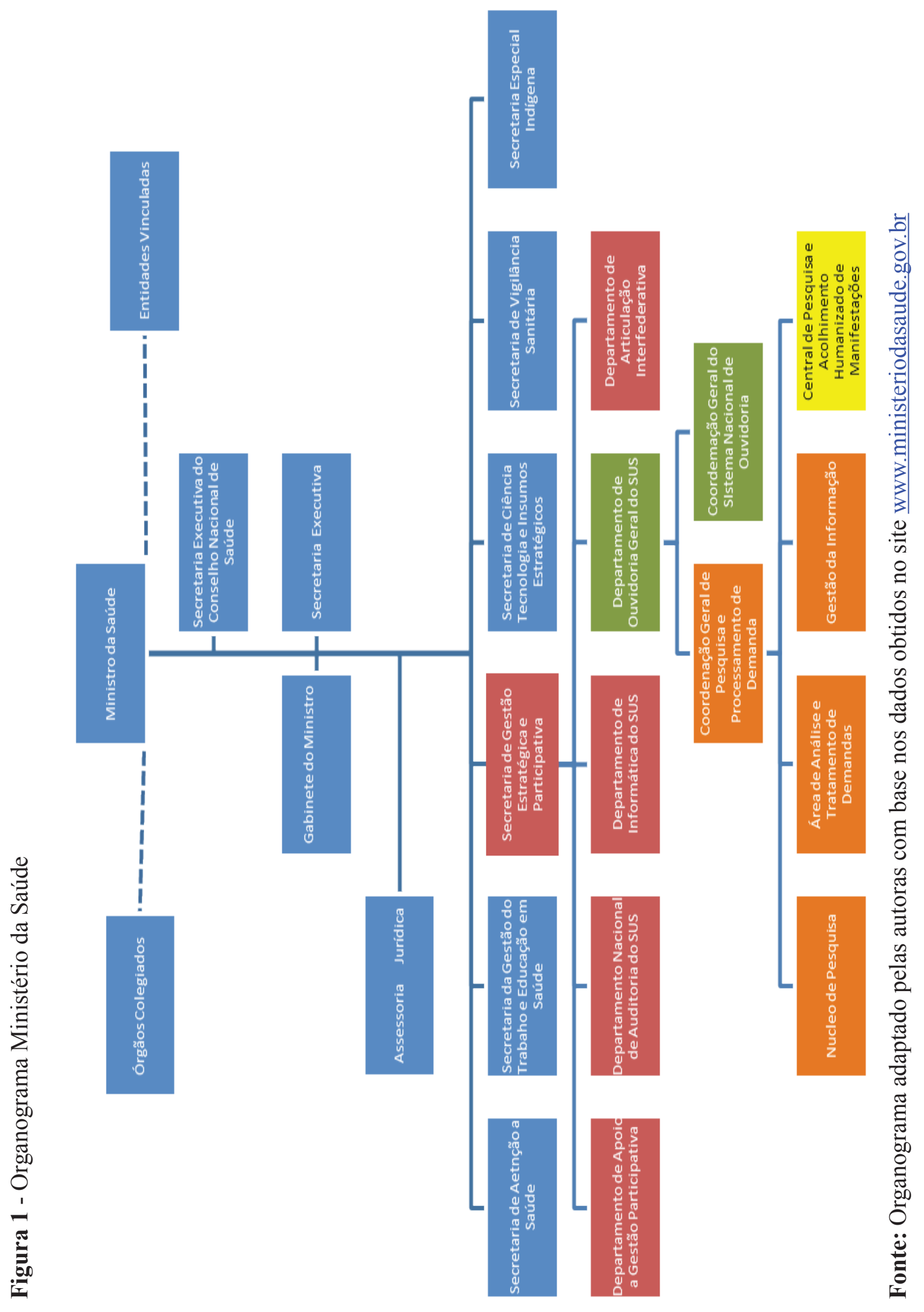

46 // Rev Tempus Actas Saúde Col 
OuvidorSUS que dentre outras funções registra as manifestações dos usuários que serão encaminhadas aos ouvidores dos órgãos responsáveis pelas respostas aos cidadãos, e que são compartilhados pelo Programa Business Intelligence.

Por se tratar de banco de acesso restrito, a obtenção dos dados foi autorizada pelo Departamento de Ouvidoria Geral do SUS ${ }^{3}$.

A pesquisa bibliográfica consistiu na seleção de livros e artigos científicos que discutissem o

3 Oficio de solicitação protocolado no Departamento sob n ${ }^{\mathrm{o}} 2500.174847 / 2012-01$. tema da ouvidoria e da democracia participativa.

\section{RESULTADOS E DISCUSSÃO}

A Ouvidoria Geral do SUS disponibiliza inúmeros canais de entrada para recebimento de manifestações dos cidadãos, tais como cartas, internet, pessoalmente ou telefone (DISQUE SAÚDE).

No ano de 2011, a Ouvidoria Geral do SUS recebeu um total de 22.510 registros, sendo 10.392 provenientes do DISQUE SAÚDE(gráfico 1).

Gráfico 1 - Demandas Cadastradas na Ouvidoria Geral do SUS, por canal de entrada em 2011.

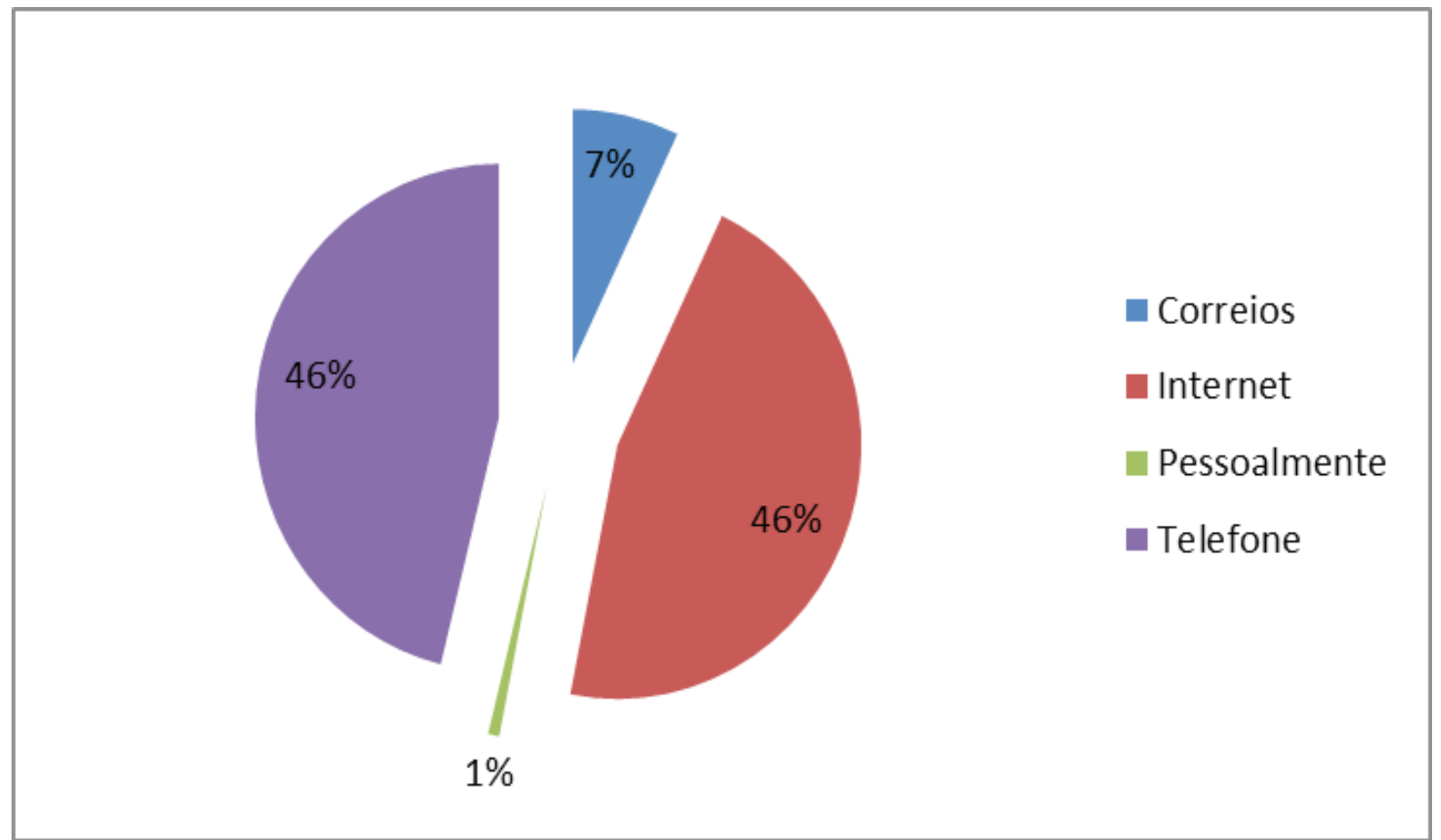

Fonte: Elaborado pelas autoras com base nos dados do Sistema OuvidorSUS/Datasus/Ministério da Saúde.

O serviço DISQUE SAÚDE não apresentou, no ano de 2011, um registro linear no seu acesso pelos cidadãos (gráfico 2). Foram observados meses com um volume de mais de 1000 registros (fevereiro, março, novembro e dezembro), e meses com registros que variavam entre 600 e 700 chamadas (janeiro e abril).
Importante destacar o número de registros observado no mês de fevereiro (16\%), bem acima dos números observados ao longo do ano de 2011. Um dos motivos que poderia explicar esse aumento foi lançamento do Programa Farmácia Popular do Brasil, por meio da Portaria Ministerial n ${ }^{\circ} 184$ de 03 de fevereiro 
de 2011, o que poderia justificar a busca de informações, reclamações e críticas ao novo programa, através do DISQUE SAUDE.
A baixa demanda nos meses de agosto a outubro, segundo informações contidas no Relatório Gerencial de 2011 do DOGES ${ }^{(10)}$, se deu em virtude do processo da modernização

Gráfico 2 - Quantidadade de demandas cadastradas mensalmente no DISQUE SAÚDE no ano de 2011.

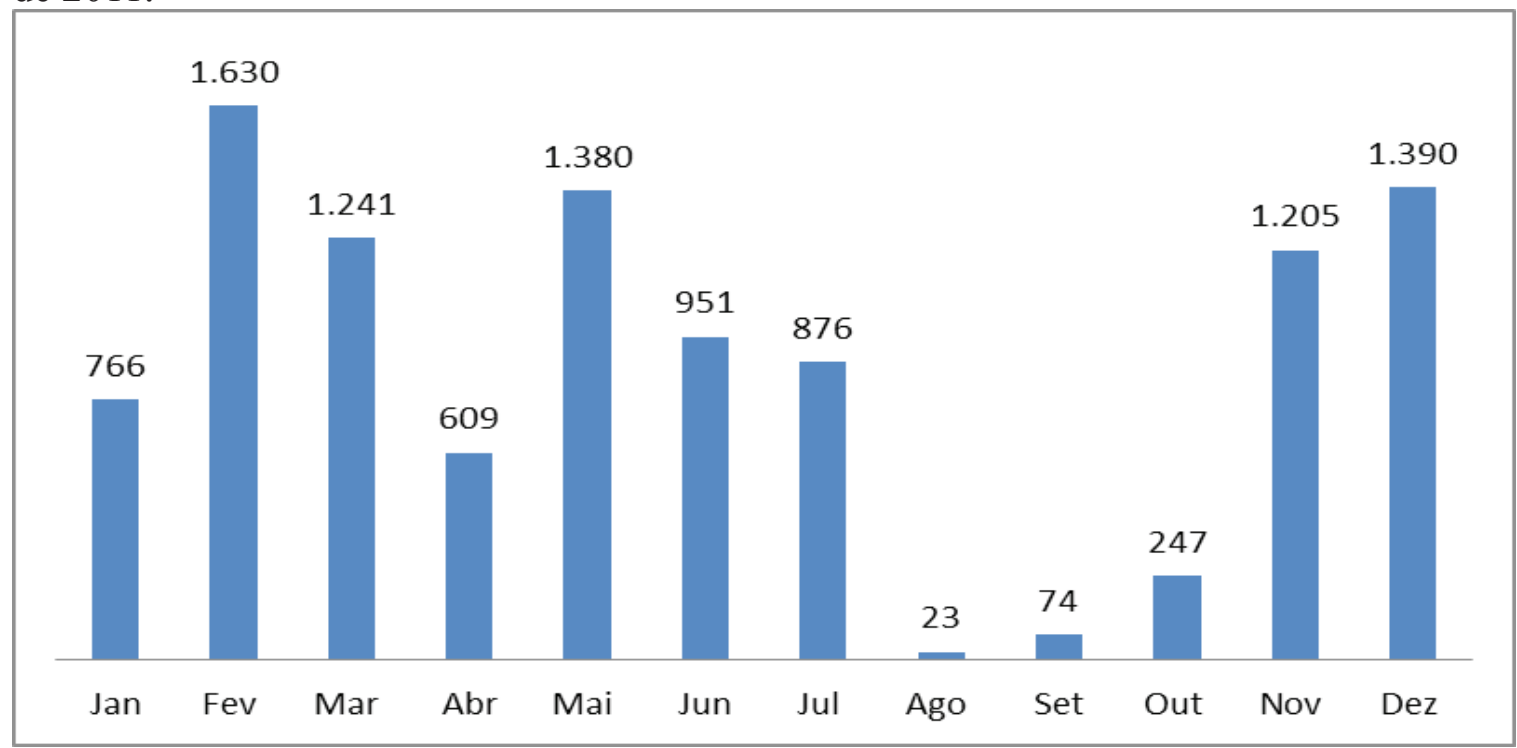

Fonte: Elaborado pelas autoras com base nos dados do Sistema OuvidorSUS/Datasus/Ministério da Saúde.

do DISQUE SAÚDE.

Essas manifestações registradas no DISQUE SAÚDE, seguem o fluxo estabelecido no Guia de Orientações Básicas para implantação de Ouvidorias do SUS. Conforme o referido documento, as manifestações após registradas são analisadas, onde então são verificados se há dados suficientes para encaminhamento do processo. Também nessa fase é avaliada se a demanda deve correr em sigilo, e qual o local para o seu encaminhamento ${ }^{(11)}$.

Apenas são encaminhadas as manifestações com dados suficientes. Esse encaminhamento é feito para a área responsável pela solução da questão.

Ao longo desse processo as manifestações são constantemente acompanhadas pela Ouvidoria Geral do SUS. Esse acompanhamento é necessário para que haja um monitoramento da resolução do tema, e, se necessário, agilizar e intermediar as ações necessárias.

O acompanhamento pela Ouvidoria também tem a dimensão de avaliação da resposta concedida pelo setor/órgão responsável pela demanda. Em caso de resposta insatisfatória, a demanda é encaminhada imediatamente para instância superior para nova avaliação concedida a resposta satisfatória, a demanda é fechada no sistema ${ }^{(12)}$.

Ao longo desse processo, o cidadão é informado sobre o trâmite da demanda, em todas as suas fases. 
Na presente pesquisa foi analisada ainda a distribuição das manifestações protocoladas no DISQUE SAÚDE por regiões (gráfico 3). Por essa análise, conclui-se que a região CentroOeste concentrou $48 \%$ do total das demandas, seguida pela região Sudeste (32\%) e Nordeste (11\%).

No detalhamento das demandas encaminhadas verificou-se que na região Centro-Oeste, o Distrito Federal foi a unidade da federação responsável pelo maior percentual de cadastramento das demandas com 92,78\%, e, segundo consta no Relatório Gerencial 2011 do Departamento de Ouvidoria Geral do SUS esse número se dá pelo fato do Distrito Federal englobar todas as áreas técnicas do Ministério da Saúde ${ }^{(10)}$.

Não obstante essa informação constante no Relatório, se faz necessário um estudo mais detalhado e aprofundado para investigar esse

Gráfico 3 - Total de Demandas por Região

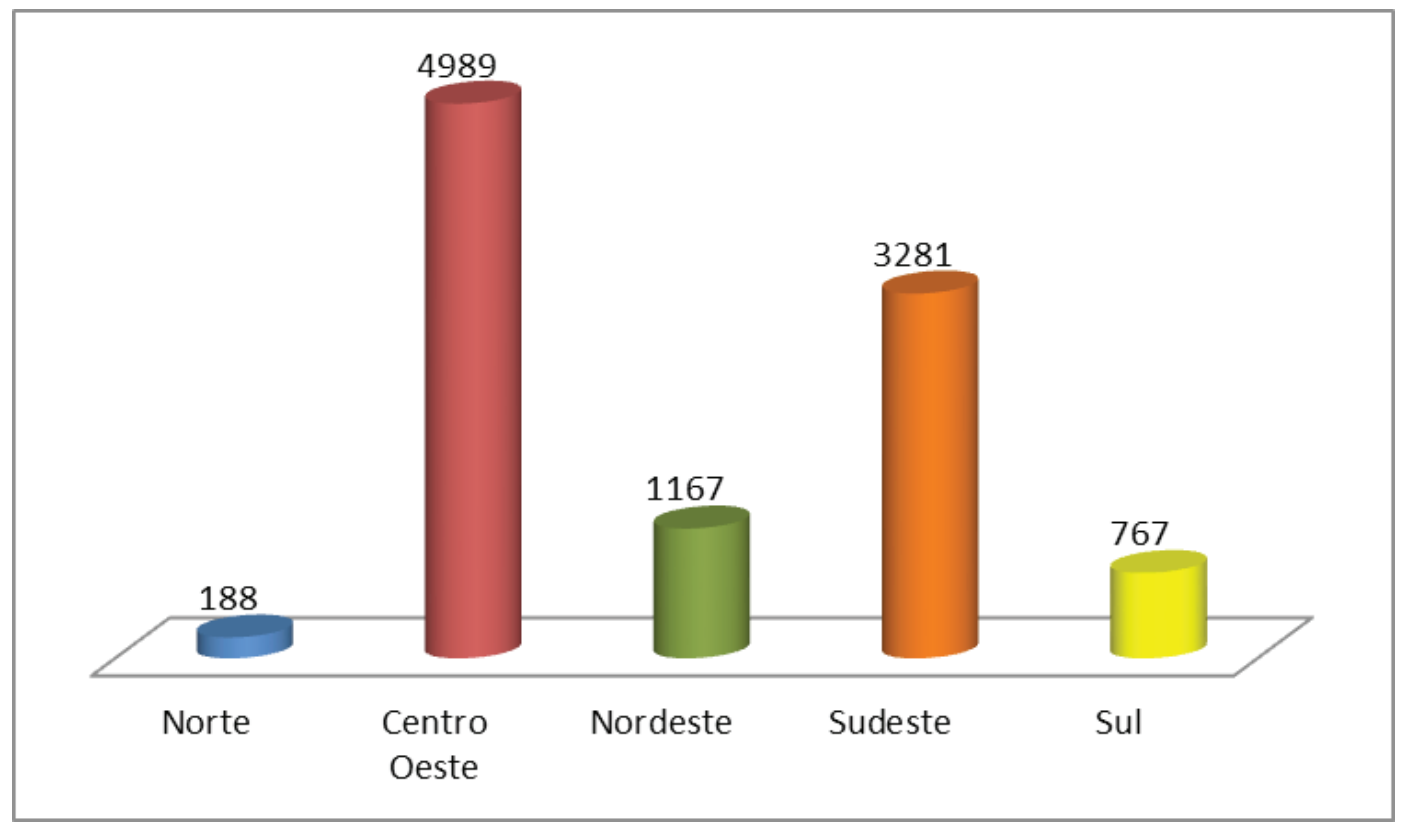

Fonte: Elaborado pelas autoras com base nos dados do Sistema OuvidorSUS/Datasus/Ministério da Saúde.

resultado.

Após o acolhimento das manifestações no DISQUE SAÚDE, eles são categorizadas por tema, para permitir um melhor encaminhamento e solução da demanda. Essa categorização é realizada tendo como base a classificação prévia de 22 assuntos, conforme estabelecido em documento próprio da Ouvidoria Geral do SUS intitulado Manual de Tipificação do Sistema Informatizado OuvidorSUS. Alguns temas possuem ainda uma tipificação em subtemas.
Os temas são tipificados nas seguintes categorias: (1) alimentos; (2) assistência à saúde; (3) assistência farmacêutica; (4) assistência odontológica; (5) assuntos não pertinentes; (6) cartão SUS; (7) comunicação; (8) conselho de saúde; (9) estratégia de saúde da família/programa de agentes comunitários de saúde - ESF/PACS; (10) financeiro; (11) gestão; (12) orientações de saúde; (13) ouvidoria do SUS; (14) produtos para saúde/ correlatos; (15) Programa Farmácia Popular do Brasil; (16) Programa Farmácia Popular 
- sistema co-pagamento; (17) Programa

Nacional de Controle do Tabagismo (PNCT);

(18) Programa Nacional de DST e AIDS; (19)

SAMU; (20) transporte; (21) vigilância em saúde e (22) vigilância sanitária ${ }^{(12)}$.

Importante ressaltar que essa tipificação é seguida não apena pelo sistema de Ouvidoria Geral do SUS, mas por todas as demais unidades de ouvidoria implantadas com o apoio do MS, e que também se utilizam do Sistema
OuvidorSUS.

A pesquisa apontou que as manifestações acolhidas no ano de 2011 concentram-se principalmente em torno de 5 temas - Programa Farmácia Popular - sistema co-pagamento (3.431); assistência farmacêutica (1.701); assistência à saúde (1.599); gestão (1.268) e Programa Farmácia Popular do Brasil (392) (gráfico 4).

Gráfico 4 - Temas mais cadastrados no DISQUE SAUDEno ano de 2011

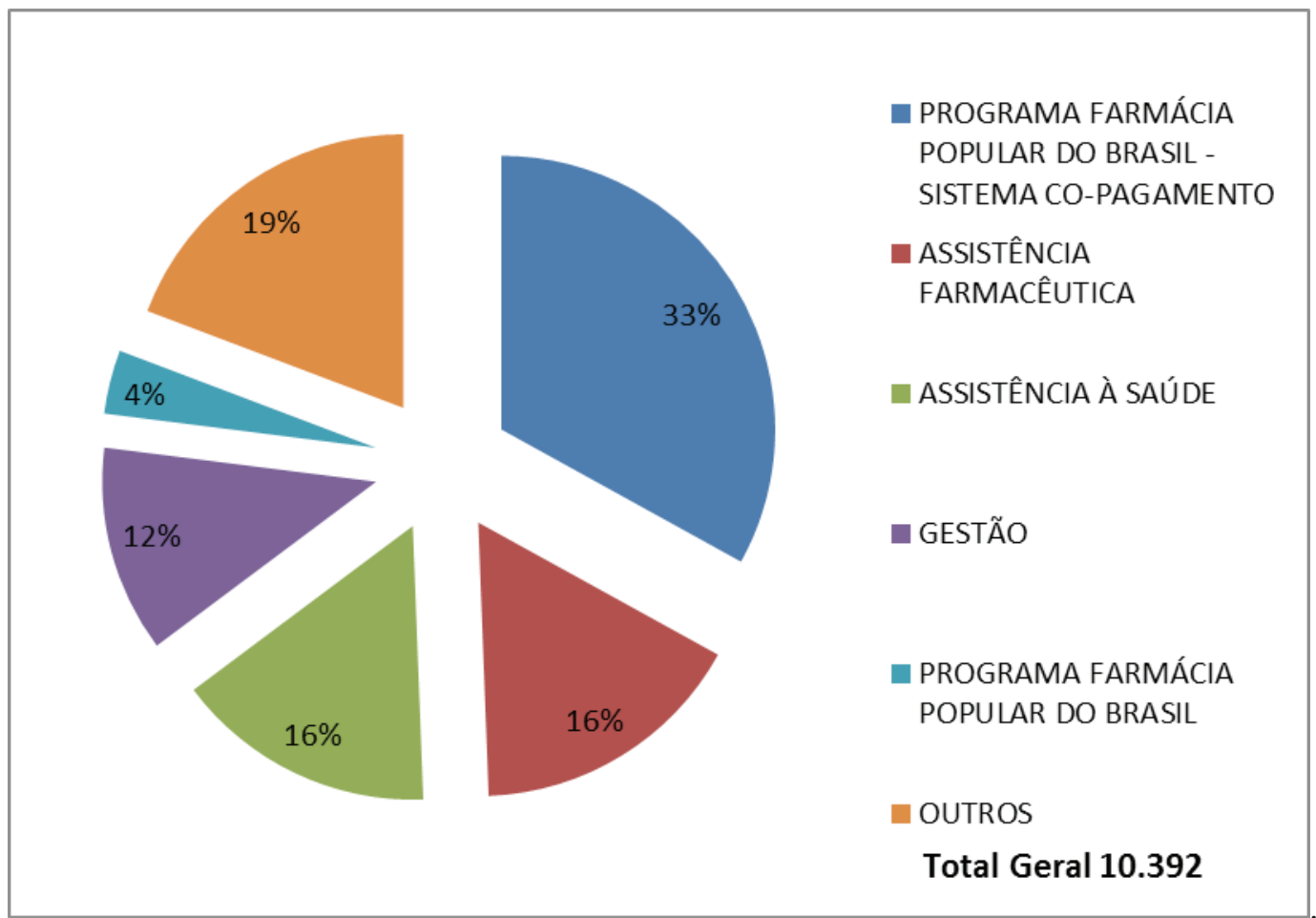

Fonte: Elaborado pelas autoras com base nos dados do S1stema OuvidorSUS/Datasus/Ministério da Saúde. 
Segundo o referido Manual de Tipificação, há uma diferenciação entre o tema Programa Farmácia Popular do Brasil e o Programa Farmácia Popular - sistema co-pagamento. O primeiro se apresenta como uma política pública que tem como principal objetivo ampliar o acesso de medicamentos essenciais à população brasileira, mediante a venda desses produtos a baixo custo, ao passo que o segundo é uma modalidade do primeiro, e consiste em um acordo firmado com estabelecimentos farmacêuticos privados para a venda, a baixo custo, de medicamentos específicos para hipertensão, diabetes, além de anticoncepcionais. Nesses casos, o Ministério da Saúde subsidia $90 \%$ do valor do fármaco ${ }^{(12)}$.

No tema assistência farmacêutica, o Manual de Tipificação descreve que neles estão englobadas as manifestações relacionadas à solicitação de medicamentos, falta de medicamentos na rede SUS, inclusão de novos fármacos nas listagens oficiais, bem como manifestações que se relacionem a irregularidades na distribuição de medicamentos de distribuição gratuita ${ }^{(12)}$.

Por assistência à saúde entende-se as demandas que abordam procedimentos médicos em seus vários níveis de complexidade - ambulatorial, hospitalar e tratamento domiciliar. Estão inseridas nesse campo também os assuntos relacionados com transplante de órgãos.

Por fim, o Manual define como as manifestações relacionadas à gestão as situações que envolvam o gerenciamento necessário as funções do SUS ${ }^{(12)}$.

As demais manifestações por representarem uma grande fragmentação de temas, com baixo percentual de demanda, foram agregadas na categoria outros. Compuseram a categoria outros, informações relacionadas aos seguintes temas: vigilância sanitária; vigilância em saúde; produtos para saúde/correlatos; estratégia de saúde da família/programa de agentes comunitários de saúde-ESF/PACS; transporte; ouvidoria do SUS; financeiro; comunicação; assistência odontológica; SAMU; alimento; orientações em saúde; cartão SUS; programa nacional de DST e AIDS; programa nacional de controle do tabagismo - PNCT; assuntos não pertinentes e conselho de saúde.

O que se conclui é que a temática do acesso aos medicamentos seja disposta em política específica ou não, foi o grande tema tratado no ano de 2011, perfazendo $53 \%$ do total de manifestações acolhidas pelo DISQUE SAÚDE.

Ademais, outro fato que também justifica o grande número de manifestações recebidas sobre esse tema $37 \%$ foi o lançamento do Programa Farmácia Popular do Brasil, em fevereiro de 2011.

Por fim, foi observada a classificação dessas demandas, conforme a tipificação estabelecida novamente no Manual de Tipificação do Sistema Informatizado OuvidorSUS.

A classificação compreende as seguintes categorias: (i) denúncia; (ii) reclamação; (iii) informação; (iv) solicitação; (v) elogio e (vi) sugestão.

Por denúncia o Manual conceitua como a manifestação que indica irregularidade, ou indícios, na administração e no atendimento, 
seja em entidade pública ou privada. A reclamação é um relato de insatisfação com

Gráfico 5 - Classificação das demandas cadastradas na Central em 2011

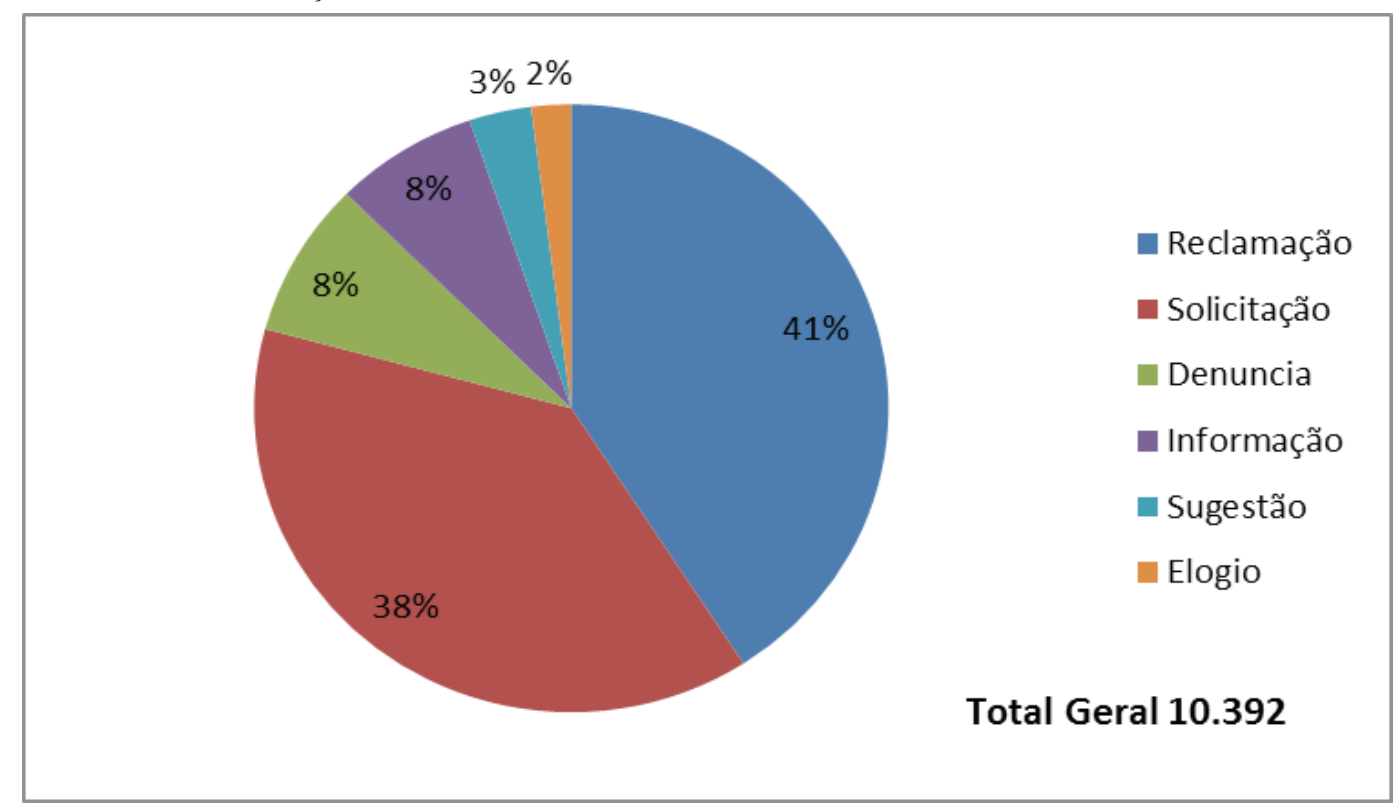

Fonte: Elaborado pelas autoras com base nos dados do Sistema OuvidorSUS/Datasus/Ministério da Saúde.

ações e/ou serviços de saúde, sem, contudo ter o caráter de requerimento. Essa dimensão de requerimento transforma a manifestação para uma solicitação ${ }^{(12)}$.

Por informação o manual dispõe ser o questionamento que se faz sobre o sistema ou assistência de saúde ${ }^{(12)}$.

O elogio consiste na manifestação, por parte do cidadão, de satisfação ou agradecimento, pelos serviços prestados pelo SUS. A sugestão, por sua vez, é a manifestação que propõe algum tipo de ação destinada à melhoria do SUS ${ }^{(12)}$.

Os dados analisados demonstram que as manifestações acolhidas pelo DISQUE SAÚDE em 2011, são majoritariamente de reclamações 4.246, seguido pelo registro de solicitação 3.984 (gráfico 5).
Esse resultado aponta que o DISQUE SAÚDE pode funcionar como importante instrumento de gestão, uma vez que indica as fragilidades de seu sistema, de forma detalhada, além de instrumento de comunicação entre Estado e sociedade.

Bonavides ${ }^{(1)}$, afirma que a cidadania é manifestada pela via participativa, através da manifestação da vontade de cada individuo da sociedade, legitimamente habilitado a intervir no processo decisório e governativo. Desse modo, a possibilidade de poder elogiar, denunciar, solicitar, reclamar, sugerir e pedir informações através desse sistema implantado pela Ouvidoria é a manifestação viva do exercício de cidadania.

Os resultados indicam que a população está cada vez mais compreendendo o seu papel de protagonista de um processo de mudanças. Nesse sentido, a participação cidadã precisa 
ser exercitada para que os resultados sejam exequíveis e a gestão seja consolidada nas necessidades sociais do povo e a gestão, por sua vez, tem que fazer cumprir seu papel de ser participativa.

\section{CONSIDERAÇÕES FINAIS}

A participação cidadã deve ser exercida diuturnamente, como forma de fortalecimento do papel dessa nova sociedade civil, mais atenta e atuante no processo de condução da coisa pública.

O DISQUE SAÚDE tem se mostrado um importante canal de comunicação entre o Estado e a sociedade, principalmente porque sua forma de execução - atendimento telefônico gratuito - possibilita um amplo acesso dos cidadãos, independente do local de residência, nível de escolaridade, condição financeira, etc.

Ademais, também demonstrou ser importante instrumento de gestão, pois reúne informações que devem ser analisadas quando do processo de tomada de decisão, já que o DISQUE SAÚDE também coleta denúncia, críticas e elogios ao SUS.

Nesse sentido é que se reconhece no serviço do DISQUE SAÚDE, importante instrumento para fortalecimento da participação cidadã e gestão democrática das políticas públicas em saúde.

\section{REFERÊNCIAS}

1. BONAVIDES, Paulo. A Constituição Aberta - Temas políticos e constitucionais da atualidade, com ênfase no Federalismo das Regiões. São Paulo: Malheiros, 2004.

2. TEIXEIRA. Elenaldo Celso. O local e o global: limites e desafios da participação cidadã. 2 ed. São Paulo: Cortez; Recife:EQUIP; Salvador: UFBA, 2001.

3. DAHL, Robert A. Sobre a democracia. trad. Beatriz Sidou, Brasília: Universidade de Brasília, 2001.

4. CARDOSO, Antônio Semerado Rito. Ouvidoria como instrumento de mudança. Brasília: IPEA, 2010.

5. RICHE, Cristina Ayoub. Ouvidoria, Caminho para a Civilidade e o Diálogo. Revista Organicon. Ano 7, n. 12. São Paulo: 2010.

6. ALVES, Sandra Mara Campos. Democracia participativa e a consulta pública na Agência Nacional de Saúde Suplementar. In: Temas Atuais de Direito Sanitário, Maria Célia Delduque (Org.) Brasília: CEAD/FUB, 2009, p. 45-63.

7. BRASIL. Ministério da Saúde. Conselho Nacional de Saúde. Relatório Final da $13^{\text {a }}$ Conferência Nacional de Saúde: Saúde e Qualidade de vida: políticas de estado e desenvolvimento. Brasília, 2008.

8. BRASIL. Decreto $\mathrm{n}^{\circ} 4726 / \mathrm{GM} / \mathrm{MS}$, de 09 de junho de 2003. Disponível em: http:/portal.saude.gov.br/portal/arquivos/pdf/ decreto 4726 2003 estrutura ms.pdf. Acesso em: 01 de dez. de 2012.

9. BRASIL. Decreto $\mathrm{n}^{\circ} 7797 / 12 / \mathrm{CS} / \mathrm{PR}$, de 09 de junho de 2003. Disponível em: http:// www.planalto.gov.br/ccivil_03/Ato20112014/2012/Decreto/D7797.htm. Acesso em: 12 de nov. de 2012.

10. BRASIL. Ministério da Saúde. Departamento de Ouvidoria Geral do SUS. Relatório Gerencial 2011. Disponível EM: 
http://portal.saude.gov.br/portal/arquivos/pdf/ relatorio gerencial 2011.pdf. Acesso em: 12 de nov. de 2012.

11. BRASIL. Ministério da Saúde. Secretaria de Gestão Participativa. Departamento de Ouvidoria Geral do SUS. Guia de Orientações Básicas para Implantação de Ouvidorias do SUS. 2010. Disponível em: www.saude.mt.gov.br/arquivo/2627. Acesso em: 10 de nov. de 2012 .

12. BRASIL. Ministério da Saúde. Secretaria de Gestão Participativa. Departamento de Ouvidoria Geral do SUS. Manual de Tipificação do Sistema Informatizado OuvidorSUS. 2011. Disponível em: http://portal.saude.gov.br/portal/arquivos/ pdf/manualdetipificacao_ouvidoria_2012.pdf. Acesso em: 12 nov. de 2012.

Artigo apresentado em: 24/02/2013 Artigo aprovado em: 10/03/2013 Artigo publicado no sistema em: 02/04/2013 